\title{
Relações econômicas e garantia de direitos: estudo de caso na comunidade Jenipapo-Kanindé
}

\section{Economic relations and rights guarantee: case study in the Jenipapo-Kanindé community}

iD Jefrei Almeida Rocha'

iD Paulo Venício Braga de Paula²

iD Rosendo Freitas de Amorim 3

Resumo: O presente artigo resulta de pesquisa bibliográfica, de cunho qualitativo e com fontes diversas de coleta de informações. Objetivouse compreender os elementos envolvidos nas relações econômicas desenvolvidas na Comunidade Indígena da Lagoa Encantada, localizada no município de Aquiraz - Ce. A fundamentação teórico-metodológica é de cunho qualitativo, mediante uma abordagem bibliográfica, documental e de estudo de campo. Foi realizada coleta de dados, observação, diários e notas de campo, além de entrevista semiestruturada. Os

\footnotetext{
1 Mestre em Computação Aplicada pela UECE/IFCE, Especialista em Ensino de Língua Portuguesa e Literatura (2007). Possui graduação em Letras pela Universidade Estadual do Ceará (2002). Professor de língua Portuguesa da Rede Pública Estadual do Ceará. Professor de Nível Superior de cursos de Graduação e Pós-Graduação. E-mail: jefrei_rocha@hotmail.com ORCID: https:// orcid.org/0000-0003-3438-5474 ID Lattes: 8397185361039339

2 Mestre em Planejamento em Políticas Públicas pela Universidade Estadual do Ceará. Especialista em Informática Educativa pela Universidade Estadual do Ceará, Especialista em Administração Escolar pela Universidade Estadual Vale do Acaraú - UEVA. Licenciatura Plena em História, pela Universidade Estadual do Ceará. Professor de Nível Superior de cursos de Graduação e Pós-Graduação. Professor da Rede Pública do Estado do Ceará. E-mail: pauloveniciobg@gmail.com ORCID: https://orcid.org/00000002-4226-1669 ID Lattes: 3821442647222685

3 Doutor em Sociologia pela Universidade Federal do Ceará (2001), Mestre em Sociologia pela Universidade Federal do Ceará (1995). Possui estágio pós-doutoral em Saúde Coletiva pelo Instituto de Saúde Coletiva (ISC) da Universidade Federal da Bahia (UFBA).Especialista em Lógica Dialética pela Universidade Estadual do Ceará (1989). Licenciado em Filosofia e História pela Universidade Estadual do Ceará (1983). Professor Titular do Programa de Pós-Graduação em Direito Constitucional da Universidade de Fortaleza (UNIFOR). Assessor técnico da Secretaria de Educação do Estado do Ceará (SEDUC). E-mail: rosendo@unifor. br ORCID: https://orcid.org/0000-0003-1498-8999 ID Lattes: 5788651334387181
} 
dados foram analisados por meio de tratamento interpretativo e crítico dos conteúdos. Constatou-se que, por conta das políticas de integração das comunidades indígenas, poderia o índio abandonar sua cultura e suas tradições, constituindo a força de trabalho necessária para o desenvolvimento econômico do país. Não seriam obstáculos e não prejudicariam o desenvolvimento da pátria. À luz da Constituição Federal de 1988, que significou um verdadeiro avanço no ordenamento jurídico brasileiro, considera-se que a legislação específica atual rompeu com a anterior, trazendo ampla garantia de direitos às comunidades indígenas. O fenômeno econômico, a pousada na Lagoa da Encantada criada pelos Jenipapo-Kanindé, simboliza um amálgama entre o direito natural e o direito positivo, entre as atividades produtivas tradicionais e uma nova atividade de produção de renda, entre a tradição artesã e de cultivo de alimentos, com o setor de serviços.

Palavras-chave: Direito natural; Direito Econômico; Relações econômicas; Direito de povos originários.

\begin{abstract}
This article is the result of bibliographic research, of a qualitative nature and with different sources of information collection. The objective was to understand the elements involved in the economic relations developed in the Lagoa Encantada Indigenous Community, located in the municipality of Aquiraz - Ce. The theoretical-methodological basis is of a qualitative nature, through a bibliographic, documentary and field study approach. Data collection, observation, diaries and field notes were carried out, in addition to semi-structured interviews. The data were analyzed through interpretative and critical treatment of the contents. It was found that, due to the integration policies of the indigenous communities, the Indian could abandon his culture and traditions, constituting the necessary workforce for the country's economic development. They would not be obstacles and would not hinder the development of the country. In light of the 1988 Federal Constitution, which meant a real advance in the Brazilian legal system, the current specific legislation is considered to have broken with the previous one, bringing ample guarantee of rights to indigenous communities. The economic phenomenon, the pousada in Lagoa da Encantada created
\end{abstract}


by Jenipapo-Kanindé, symbolizes an amalgam between natural law and positive law, between traditional productive activities and a new incomeproducing activity, between the artisan tradition and the cultivation of with the service sector.

Keywords: Natural law; Economic Law; Economic relations; Right of indigenous peoples

Data de submissão do artigo: Maio de 2018

Data de aceite do artigo: Setembro de 2020 
Relações econômicas e garantia de direitos: estudo de caso na comunidade... Jefrei Almeida Rocha • Paulo Venício Braga de Paula • Rosendo Freitas de Amorim

\section{Introdução}

Entende-se o Direito como um dos mais efetivos instrumentos de controle social, provavelmente o mais eficaz, tendo em vista sua propriedade de coercibilidade garantida pelo Estado. Para Nader (2007), o Direito é entendido como o aglomerado de normas de conduta social, imposto de forma coercitiva pelo Estado, tendo como finalidade a realização da segurança, sob critérios de justiça.

Nesse sentido, pode-se entender que a harmonia da sociedade depende da aplicação efetiva, eficaz e válida do Direito, de modo a garantir que as relações interpessoais ocorram da maneira mais satisfatória possível e com o mínimo de desgaste entre os sujeitos envolvidos.

Partindo desse pressuposto, pode-se direcionar o olhar sobre a busca da satisfação jurídica no campo da economia. A relação entre Direito e Economia se dá de forma constante, a diversidade litigiosa existente nos diversos ramos do Direito envolve bens ou valores em sua relação com seu uso, posse e propriedade.

O território dessas disputas jurídicas envolve o entendimento sobre como as mesmas se constituem e, tanto nas relações sociais internas, quanto nas relações entre Estados soberanos, identificam-se várias formas de disputa jurídica, fomentando uma constante atualização do Direito em si, em sua relação com a sociedade.

Tendo em mente essa explanação inicial, buscou-se com este estudo analisar as relações jurídicos econômicos instituídas na comunidade de povos originários do município de Aquiraz, da etnia Jenipapo-Kanindé, autodenominada Comunidade da Lagoa Encantada.

Nesse litígio jurídico existe uma singularidade quanto aos sujeitos envolvidos, de um lado os povos originários cujo direito à terra é uma condição natural, por serem herdeiros das nações aqui estabelecidos antes da chegada e ocupação por parte do europeu, e do outro a população da considerada cidade grande, 
Relações econômicas e garantia de direitos: estudo de caso na comunidade... Jefrei Almeida Rocha • Paulo Venício Braga de Paula • Rosendo Freitas de Amorim

ou melhor, integrantes da população urbana representantes do poderio econômico e interesses capitalistas.

Para LIMA e MARQUESAN (2017), ao tratarem da regulamentação agrária em relação ao nativo, indicam que;

(...) momento histórico da legislação agrária do Brasil e que apresentou sérios impactos sobre as comunidades indígenas, quilombolas e aquelas que dependiam da terra para sua subsistência, foi a criação da Lei das Terras, em 1850. Eram medidas relativas à adequação da estrutura fundiária do Brasil Imperial às novas exigências econômicas do modelo social concentrador (CORDEIRO: 1989). A lei expressava que as terras não poderiam ser alteradas em sua destinação.(LIMA; MARQUESAN: 2017; 496)

Mediante esse mecanismo, os descendentes desse europeu se apossaram e legitimaram através do direito das terras pertencentes da sociedade nativa original, coube ao direito um papel determinante no estabelecimento desse domínio. Ainda de acordo com LIMA e MARQUESAN (2017), o efeito dessa legislação no Ceará foi que:

\begin{abstract}
o governo se utilizou de decreto e fez com que as terras indígenas do estado automaticamente se tornassem devolutas (CORDEIRO, 1989). Para Leite Neto (2006, p.15), “o desaparecimento dos povos indígenas, no Ceará, propagado na segunda metade do século XIX, está relacionado a este plano político promovido pela história oficial, com objetivo declarado de legitimar a desapropriação de suas terras".( LIMA; MARQUESAN: 2017; p. 496)
\end{abstract}

Os descendentes da citada comunidade Jenipapo-Kanindé, após intenso litígio sobre a posse da terra já no século XXI, venceram a contenda envolvendo seu direito à terra e obtiveram a 
Relações econômicas e garantia de direitos: estudo de caso na comunidade... Jefrei Almeida Rocha • Paulo Venício Braga de Paula • Rosendo Freitas de Amorim

demarcação de sua terra, tão necessária para a reconstrução e afirmação de sua identidade.

No contexto das relações atuais essa afirmação de identidade perpassa pela sustentabilidade desses povos. Compreendendo isso, a comunidade tomou como medida de ordem econômica a estruturação de uma pousada para receber turistas, bem como uma série de atividades que visam à geração de renda para a tribo.

Com a pesquisa, objetiva-se, inicialmente, compreender esse contexto socioeconômico; em seguida, identificar os fatos relacionados à criação da pousada, incluindo-se a percepção dos sujeitos da tribo e; finalmente, analisar as consequências e impactos dessa mudança à luz do Direito sobre as relações econômicas primárias da Comunidade da Lagoa Encantada.

Optou-se por uma metodologia de pesquisa de campo, com a realização de entrevista com os membros da comunidade responsáveis pela criação e administração da pousada, seguindo os parâmetros éticos da pesquisa científica, visando construir uma linha histórica dos fatos que desencadearam essa atividade econômica.

Acredita-se que as relações intersubjetivas dos membros da tribo possam ter sofrido uma distorção e que padrões antes pautados no entendimento do direito natural dos mais antigos, passaram por um choque com o direito positivado que o ramo empresarial exige. Assim, ao fim do trabalho, espera-se contribuir para o entendimento dos impactos do direito positivo em uma comunidade de povos originários.

\section{Metodologia}

Ao realizar uma pesquisa teórica, busca-se fazer uma releitura dos fundamentos teóricos a partir da compreensão da realidade. De acordo com Minayo (1994), a relação entre pesquisador e seu campo de estudo se estabelece definitivamente na investigação social. 
Relações econômicas e garantia de direitos: estudo de caso na comunidade... Jefrei Almeida Rocha • Paulo Venício Braga de Paula • Rosendo Freitas de Amorim

Quanto à abordagem, a pesquisa é qualitativa, no sentido de aprofundar a compreensão e descrição dos fenômenos em análises referentes a um grupo social estudado, bem como da dinâmica relacional entre a realidade e os sujeitos da pesquisa.

\begin{abstract}
A realidade social é o próprio dinamismo da vida individual e coletiva com toda a riqueza de significados dela transbordante. Essa mesma realidade é mais rica que qualquer teoria, qualquer pensamento e qualquer discurso que possamos elaborar sobre ela. (MINAYO: 1994; 15)
\end{abstract}

Ao tratarmos da relação do direito à terra por parte do nativo na sociedade colonial brasileira, ocorre uma transcendência temporal. Na dinâmica das relações sociais, o nativo que antes não precisava justificar a legitimidade da terra por parte de um direito natural, com a ruptura social e a prevalência do direito positivo, passou a ter seus direitos constituídos negados e, em alguns casos, usurpados por aqueles que supervalorizam os aspectos econômicos e capitalistas de exploração das terras e das riquezas existentes nelas.

No que se refere à fonte das informações, utilizou-se a pesquisa bibliográfica, a documental e o estudo de campo. A coleta de dados deu-se mediante as técnicas de observação, diários e notas de campo, além de entrevista semiestruturada, tendo sido analisados os dados por meio de tratamento interpretativo e crítico dos conteúdos, bem como já informado, respeitando os critérios éticos do desenvolvimento e execução de pesquisas científicas.

De acordo com Fonseca (2002), a abordagem qualitativa possui um maior enfoque na interpretação do objeto da pesquisa. Além disso, atribui-se grande importância ao contexto do objeto pesquisado, e por isso é necessária uma maior proximidade do pesquisador em relação aos fenômenos estudados.

Nesse sentido, Almeida e Freire (2008) afirmam que a pesquisa qualitativa prestigia o tratamento interpretativo, ou hermenêutico, 
Relações econômicas e garantia de direitos: estudo de caso na comunidade... Jefrei Almeida Rocha • Paulo Venício Braga de Paula • Rosendo Freitas de Amorim

dos dados e destacam três procedimentos que corroboram para o maior sucesso desse tipo de pesquisa: i. A primazia da experiência subjetiva como fonte do conhecimento; ii. $O$ estudo dos fenômenos a partir da perspectiva do outro, ou respeitando seu marco de referência, e; iii. $O$ interesse em se conhecer a forma como as pessoas experienciam e interpretam o mundo social, que também acabam por construir interativamente.

Adotam-se neste trabalho os conceitos de pesquisa bibliográfica e de pesquisa documental presentes em Gil (1994; 2008). O autor afirma que ao se realizar uma pesquisa bibliográfica somada à documental há grande capacidade de alcançar um amplo escopo de informações, bem como de promover a utilização de dados dispersos em inúmeras publicações, auxiliando também na construção, ou na melhor definição do quadro conceitual que envolve o tema proposto pelo pesquisador.

As etapas da pesquisa foram: em primeiro momento, a leitura e análise das fontes bibliográficas e documentais; em segundo momento, realizou-se a elaboração das perguntas a serem utilizadas na entrevista com os sujeitos; na terceira etapa, concretizou-se com a visita à comunidade indígena Jenipapo-Kanindé, as observações in loco e a realização das entrevistas; no quarto momento, consolidou-se análise dos dados e, finalmente, no quinto e último momento, encerrou-se a pesquisa com a elaboração das considerações finais e da edição do texto deste artigo.

Por fim, ressalta-se que os sujeitos entrevistados manifestaram consentimento livre e esclarecido, todos maiores de dezoito anos, e tiveram a garantia de que a divulgação dos nomes seria apenas daqueles que não desejassem o sigilo. Foi observado o que determina a RESOLUÇÃO n 466, de 12 de dezembro de 2012, bem como a RESOLUÇÃO n 510, de 7 de abril de 2016, e mais especificamente ao art. 13 da 510/2016, no tocante à autorização para realização da pesquisa. Todos os participantes fizeram menção à importância de se manifestar e contar sua história, autorizando que os nomes fossem citados. 


\section{Direito Natural e Direito Positivo: interface em comu- nidades indígenas}

Apesar das comunidades de povos originários serem, em sua essência, sociedades de tradição oral que possuem todo seu plano cultural reproduzido oralmente, gerando um direito costumeiro cujas relações se orientam a partir das crenças e tradições, seria um engano crer que esses povos mantivessem intactas suas relações pessoais e os meios de subsistência dos membros da tribo, em meio ao desenvolvimento da sociedade, bem como o avanço da tecnologia.

É possível estabelecer encontrar similitudes e repouso dessa forma de direito, existente nas comunidades primitivas, com a origem do direito, o problema de sua existência e a dualidade com o direito positivado. Segundo (NADER:2012; 192), "os jusnaturalistas apresentam uma concepção dualista, convictos de que, paralelamente a ordem institucionalizada pelo Estado, haveria o Direito Natural, ordem não escrita, não promulgada pelos homens".

O direito costumeiro vivenciado pelos nativos pode ser entendido a partir o princípio de que, no processo de sociabilidade, os seres humanos organizam-se também a partir de uma normatividade.

O direito costumeiro dos nativos da América é uma expressão dessa normatividade.

A existência do Direito Natural se justifica por uma cadeia de raciocínios lógicos, sem recurso a dogmas. Como todo ser, a pessoa possui natureza e se dispõe a realizar fins. Estes sofrem condicionamentos ditados pela natureza. Os fins não são um todo cerrado sem alternativas, mas um leque de amplas possibilidades de realizações. Os fins são aqueles que a natureza do homem e do mundo físico permitem e não encontram censura na razão. O Direito Natural é uma tutela de fins. Seus princípios consideram a natureza humana e os fins que os homens buscam. (Nader: 2012; 192) 
Relações econômicas e garantia de direitos: estudo de caso na comunidade... Jefrei Almeida Rocha • Paulo Venício Braga de Paula • Rosendo Freitas de Amorim

E como princípio essas sociedades nativas entendiam que a terra como espaço não era uma propriedade e sim algo comum pertencente a todos, que mediante o trabalho poderia prover o sustento da comunidade.

Essa mentalidade se mantém imaculada até o contato com o colonizador europeu, cujo projeto ocupacional da terra possui outro sentido, um sentido da propriedade privada, tanto para o Estado como para o particular, sendo a forma de garantir essa posse que ocorre mediante ocupação forçada, somada a outros estratagemas com o Direito positivo.

Reforça-se a realidade que constantemente se apresenta, de um lado os povos originais com seu direito costumeiro que não regula o direito à propriedade privada e, por isso, é atacado e desapropriado da posse de sua terra, e do outro o colonizador que mediante um direito escrito busca consolidar sua posse.

Faz-se mister investigar causas e consequências dessa maior aproximação entre culturas de produção com padrões estruturalmente bem distintas, visando compreender outros fenômenos similares e servir de embasamento para outros estudos.

\subsection{Povos originários: características econômicas e o direito natural}

O Direito Natural ou Jusnaturalismo é o conjunto de normas e direitos natos, ou seja, o indivíduo de uma determinada sociedade, já nasce com determinados direitos e deveres naquela sociedade, como exemplo mais comum e universal "o direito à vida". Entendese que o Direito Natural tem servido de base para o Direito Positivo. Com o avanço e crescimento da população e, consequentemente, das sociedades, tornou-se necessário positivar o direito natural, no entanto, muitas sociedades ainda se baseiam no direito natural; inclusive como forma de manutenção de sua identidade cultural.

De acordo com Nader (2007; 19), o Direito Natural “(...) corresponde a uma ordem de justiça que a própria natureza ensina 
Relações econômicas e garantia de direitos: estudo de caso na comunidade... Jefrei Almeida Rocha • Paulo Venício Braga de Paula • Rosendo Freitas de Amorim

aos homens pelas vias da experiência e da razão, não pode ser admitido como um processo de adaptação social". Ainda segundo Nader:

O Direito Natural não é escrito, não é criado pela sociedade, nem é formulado pelo Estado. Como o adjetivo natural indica, é um Direito espontâneo, que se origina da própria natureza social do homem e que é revelado pela conjugação da experiência e razão. É constituído por um conjunto de princípios, e não de regras, de caráter universal, eterno e imutável. Como exemplos maiores: o direito à vida e à liberdade. (NADER:2007; 98-99).

Nesse sentido, ao tratar das bases conceituais do Direito Natural, Galvão de Sousa $(1977,76)$ afirma que o “caráter teleológico da natureza implica um conceito dinâmico vinculado à condição humana, quando o homem se trata, e, portanto, à sua vivência histórica". O autor defende o entendimento da "natureza" como o impulso que direciona o homem à realização de seu propósito de existência e compara ao que Santo Tomás de Aquino denominou de ius gentium.

\begin{abstract}
Um exemplo sumamente esclarecedor é o da propriedade privada, que é um direito natural não no sentido de ser estabelecido imediatamente pela natureza, mas "pela razão dos homens para a utilidade da vida humana", ou seja, sem alteração da lei natural, como um acréscimo feito a esta pela naturalis ratio. (GALVÃO DE SOUSA: 1977; 76-7).
\end{abstract}

As tribos indígenas, ou melhor, as comunidades de povos originários são exemplos desse tipo de sociedade, pois guardam seus costumes, suas normas, sua cultura. Não há diferenciação de classes sociais dentro de uma tribo, existe apenas a hierarquia natural que deve ser respeitada. A terra em que habitam pertence aos membros da tribo e a caça é dividida entre todos. O Pajé é o líder espiritual e curandeiro do grupo e o Cacique o chefe da tribo 
Relações econômicas e garantia de direitos: estudo de caso na comunidade... Jefrei Almeida Rocha • Paulo Venício Braga de Paula • Rosendo Freitas de Amorim

que orienta e organiza os índios de acordo com, nas palavras de Nader, "um Direito espontâneo, que se origina da própria natureza social do homem e que é revelado pela conjugação da experiência e razão"(2007; 98-99).

Dessa forma, compreende-se que existe uma ordem, uma hierarquia e direitos dentro de uma tribo, mas estes direitos não são positivados e sim naturais: os curumins (crianças) são educados pelos pais dentro desse direito natural e aprendem os seus costumes e tradições que irão repassar quando tiverem seus filhos, para que assim se perpetue o respeito, o conhecimento e a cultura da tribo, e todos possam alcançar sua finalidade.

\subsection{As obrigações e a proteção determinadas com o Direito Positivo}

Após a promulgação da Constituição Federal de 1988 consolidaram-se as garantias individuais e coletivas de todos os povos. Obviamente, o direito dos povos indígenas começou a ser reconhecido, isto é, o direito à diferença de costumes, de organizações sociais, de tradições, de manutenção da língua materna e processos de ensino. O texto constitucional explicita isso no Capítulo VIII da Constituição, intitulado "Dos Índios", em seus artigos 231 e 232.

De acordo com o Art. 231:

São terras tradicionalmente ocupadas pelos índios as por eles habitadas em caráter permanente, as utilizadas para suas atividades produtivas, as imprescindíveis à preservação dos recursos ambientais necessários ao seu bem-estar, e as necessárias à sua reprodução física cultural, segundo seus usos, costumes e tradições. (BRASIL: 1988).

Vale destacar que o Estado tem o dever constitucional de realizar a demarcação das terras indígenas, garantindo e reconhecendo a posse permanente da terra e o usufruto exclusivo das riquezas 
Relações econômicas e garantia de direitos: estudo de caso na comunidade... Jefrei Almeida Rocha • Paulo Venício Braga de Paula • Rosendo Freitas de Amorim

existentes no solo, nos rios e lagos das terras ocupadas. Além disso, destaca-se que a fiscalização, proteção e o respeito a todos os bens, sejam materiais ou imateriais, cabe também à União.

Complementa o disposto no Art. 232 da CF: "os índios, suas comunidades e organizações são partes legítimas para ingressar em juízo em defesa de seus direitos e interesses, intervindo o Ministério Público Federal em todos os atos do processo". Daí, resulta afirmarmos que o texto da Constituição traz aos povos originários importante fundamentação legal para a defesa, de garantia e de manutenção de seu direito subjetivo.

Cabe uma ressalva a respeito das terras das reservas indígenas: os povos originários detêm a posse como direito originário, mas a propriedade é da União, como determina o art. 20 da CF em seu inciso XI. Assim, como dispõe o parágrafo $6^{\circ}$ do Art. 231:

São nulos e extintos, não produzindo efeitos jurídicos, os atos que tenham por objeto a ocupação, o domínio e a posse das terras a que se refere este artigo ou a exploração das riquezas naturais do solo, dos rios e dos lagos nelas existentes, ressalvado relevante interesse público da União, segundo o que dispuser lei complementar, não gerando a nulidade e a extinção direito a indenização ou a ações contra a União, salvo, na forma da lei, quanto às benfeitorias derivadas da ocupação de boa fé.

Tendo em vista o texto constitucional e a Jurisprudência atual acerca do tópico tratado, infere-se que os direitos dos povos indígenas sobre as terras são imprescritíveis e anteriores ao Direito Positivo que o normatiza, sendo vedada a desocupação dessas terras pelas comunidades indígenas que não sejam para o próprio interesse dessas comunidades; por fatores naturais, como catástrofes; por questões de saúde pública, como epidemias; ou por questão de soberania nacional.

Voltando a questão do usufruto, o Código Civil, em seu Art. 713 , dispõe que usufruto é o "direito real de fruir as utilidades e 
Relações econômicas e garantia de direitos: estudo de caso na comunidade... Jefrei Almeida Rocha • Paulo Venício Braga de Paula • Rosendo Freitas de Amorim

frutos de uma coisa", entendimento que se complementa no Art. 718, ao regular que "o usufrutuário tem direito à posse, uso, administração e percepção dos frutos". Coube à legislação específica, o Estatuto do Índio (Lei 6.001/73), estabelecer o entendimento acerca do usufruto indígena:

\begin{abstract}
Art. 24 - O usufruto assegurado aos índios ou silvícolas compreende o direito à posse, uso e percepção das riquezas naturais e de todas as utilidades existentes nas terras ocupadas, bem assim ao produto da exploração econômica de tais riquezas e utilidades.
\end{abstract}

$\S 1^{\circ}$ - Incluem-se no usufruto, que se estende aos acessórios e seus acrescidos, o uso dos mananciais e das águas dos trechos das vias fluviais compreendidos nas terras ocupadas.

$\S 2^{\circ}$ - É garantido ao índio o exclusivo exercício da caça e pesca nas áreas por ele ocupadas, devendo ser executadas por forma suasória as medidas de polícia que em relação a ele eventualmente tiverem de ser aplicadas.

Diante do exposto, acredita-se que o direito do uso da terra e de suas riquezas pelos povos de comunidades originários, além de ser um Direito originário é, no entendimento dos autores deste trabalho, Natural, desde que não seja alienado para terceiros e nem comprometam a substancialidade da terra. Da mesma forma, ele é devidamente assegurado e regulamentado pelo Direito Positivo vigente, com fontes materiais e formais consolidadas, garantido pelo texto constitucional e pela legislação específica.

\title{
3. Análise e Discussão
}

A Comunidade da Lagoa Encantada, localizada no município de Aquiraz, dista de cerca de 40 quilômetros da capital cearense, 
Relações econômicas e garantia de direitos: estudo de caso na comunidade... Jefrei Almeida Rocha • Paulo Venício Braga de Paula • Rosendo Freitas de Amorim

Fortaleza, e registra um momento ímpar de sua história. Durante mais de trinta anos travou uma disputa entre o direito natural à posse de suas terras, contra o interesse econômico da empresa cearense de bebidas Ypióca, uma das maiores produtoras de cachaça. Dessa forma, viu o direito natural em confronto com o direito positivo alegado pela Ypióca.

No entanto, após a justiça ter garantido a posse da terra para os Jenipapo-Kanindé, a tribo compreendeu a necessidade de integrar suas tradições culturais e, inclusive o entendimento de justiça e de direito, aos costumes e justiça dos "não-índios". Abordaremos essa disputa e, em seguida, a integração do direito natural da tribo às exigências do direito positivo e da economia atual.

3.1. A disputa pela terra na Lagoa Encantada: colisão de princípios ou conflito de regras

Os habitantes da Lagoa Encantada compreendiam a terra como sendo deles, faltava-lhes o entendimento da ideia de posse, de organização social, de direitos e deveres. Não possuíam consciência de sua condição e de seus direitos. Seguiam o direito natural, assim como seus antepassados, inseridos em um direito, nas palavras de Nader (2007), originado "da própria natureza social do homem e que é revelado pela conjugação da experiência e razão". $\mathrm{E}$, até a década de 80 , não haviam sentido a necessidade de alterar essa realidade.

Tendo consciência dessa realidade e de que os membros da comunidade não possuíam a documentação legal da terra, teve início uma série de conflitos com empresas cujo interesse imobiliário logo recaiu sobre a região. Sem o registro da terra, sem registro legal que comprovasse a posse, a Empresa Moinho Dias Branco, em parceria com a então gestão municipal de Aquiraz, iniciou uma série de ameaças aos Cabeludos da Encantada, alcunha atribuída aos moradores da comunidade. 
Relações econômicas e garantia de direitos: estudo de caso na comunidade... Jefrei Almeida Rocha • Paulo Venício Braga de Paula • Rosendo Freitas de Amorim

1. Antigamente nós era conhecido como Cabeludos da Encantada. Os homens da tribo não cortava o cabelo curto. Homem e mulher tinha os cabelos de casca de cuia (sic). - fala de Preá Mano, um dos filhos da Cacique Pequena e responsável pela pousada.

Esse foi o primeiro momento de embate, no qual o direito positivo foi evocado para questionar o direito natural dos JenipapoKanindé sobre aquela terra. No entanto, a Pastoral e alguns universitários colaboraram com a comunidade para a criação do "campo do (re)conhecimento da identidade indígena Jenipapo-Kanindé". (BEZERRA: 1999; 106-147).

Essa disputa se deu na Ação Civil Pública № 006/98, movida pelo Ministério Público e pela Fundação Nacional do Índio - FUNAI, contra a empresa Moinho Dias Branco S.A Comércio e Indústria, que havia conseguido, junto ao Conselho Estadual de Meio Ambiente, uma licença de instalação de complexo turístico na região da Lagoa da Encantada.

Porém, o conflito de maior repercussão foi com a Agroindústria, tendo em vista os efeitos nocivos causados às águas da Lagoa da Encantada e demais aquíferos pertencente aos cabeludos da Encantada. Após várias disputas judiciais, e de um longo processo de análise dos hábitos dos Jenipapo-Kanindé à beira da Lagoa Encantada, em 24 de fevereiro de 2011, a decisão foi publicada no DOU, por meio da portaria de $\mathrm{n}^{\circ} 184$ do Ministério da Justiça, concedendo a posse permanente ao grupo indígena:

O MINISTRO DE ESTADO DA JUSTIÇA, no uso de suas atribuições legais e tendo em vista o disposto no Decreto $n^{\circ} 1.775$, de 8 de janeiro de 1996, e diante da proposta apresentada pela Fundação Nacional do Índio - FUNAI, objetivando a definição de limites da Terra Indígena LAGOA ENCANTADA, constante do processo FUNAI/2670/1998, 
Relações econômicas e garantia de direitos: estudo de caso na comunidade... Jefrei Almeida Rocha • Paulo Venício Braga de Paula • Rosendo Freitas de Amorim

CONSIDERANDO que a Terra Indígena localizada no município de Aquiraz, Estado do Ceará, ficou identificada nos termos do § $1^{\circ}$ do art. 231 da Constituição Federal e inciso I do art. 17 da Lei ${ }^{\circ}$ 6.001, de 19 de dezembro de 1973, como sendo tradicionalmente ocupada pelo grupo indígena Jenipapo-Kanindé;

CONSIDERANDO os termos do Despacho n 82/PRES, de 17 de agosto de 2004, do Presidente da FUNAI, publicado no Diário Oficial da União de 18 de agosto de 2004 e Diário Oficial do Estado do Ceará de 16 de dezembro de 2004;

CONSIDERANDO os termos dos pareceres da FUNAI, julgando improcedentes as contestações opostas à identificação e delimitação da terra indígena, resolve:

No - 184 - Art. $1^{\circ}$ Declarar de posse permanente do grupo indígena Jenipapo-Kanindé a Terra Indígena LAGOA ENCANTADA com superfície aproximada de 1731 há (um mil setecentos e trinta e um hectares) e perímetro também aproximado de 20 km (vinte quilômetros).

Após 31 anos de luta por seu reconhecimento, a tribo JenipapoKanindé consolidou seu direito natural por meio do direito positivo. Compreende-se que na decisão, a despeito desse caso, o amálgama entre o direito natural e o direito positivo foi o que propiciou uma decisão justa, garantindo ao homem o que lhe é devido, ou seja, garantido aos Jenipapo-Kanindé a terra que já lhe pertencia.

\subsection{Uma nova ordem na comunidade; integração e geração de renda}

Com a repercussão da história de luta da tribo JenipapoKanindé na Lagoa Encantada e por ser a tribo a possuir a primeira Cacique mulher do Brasil, Cacique Pequena (Maria de Lourdes da 
Relações econômicas e garantia de direitos: estudo de caso na comunidade... Jefrei Almeida Rocha • Paulo Venício Braga de Paula • Rosendo Freitas de Amorim

Conceição Alves), a comunidade passou a receber um maior número de turistas e pesquisadores durante todo o ano.

O coordenador do grupo, Preá Mano (Heraldo Alves), informou que a tribo tem um conselho onde são realizadas reuniões periódicas e nelas são tomadas as principais decisões da tribo.

2. A gente passa nossa cultura pros menores e garante nossa causa. Entendemos que é preciso manter integrado com as coisas de Fortaleza. Tem semana que passo muitos dias lá, nos encontros e formações com outros irmãos. (Preá Mano)

Observou-se que a comunidade tomou a decisão de não mais viver isolada e, apesar de manter sua identidade cultural, aproveitar as oportunidades. Comumente os visitantes passavam o dia na tribo e eram obrigados a retornarem a seus locais de origem, ou ficavam nas casas dos membros da tribo. Essa realidade despertou no conselho o interesse em explorar economicamente tal situação, assim como a luta jurídica com grandes empresas que buscavam explorar o potencial turístico das belas paisagens da região fez com que percebessem uma nova oportunidade de renda.

Assim, todos se organizaram para idealizar uma forma de turismo sustentável, onde foi criada a pousada da tribo, um museu indígena e trilhas ecológicas. Na hospedagem o turista tem a oportunidade não só de conhecer de perto a cultura, mas também de participar ativamente dos costumes da tribo, como participar do ritual sagrado, o preparo e bebida do Mocororó e as competições da tribo.

Fábio Nusdeo (2015) comenta sobre a esfera econômica e a ecológica:

No entanto, a imagem das duas esferas, apresentada logo no início do capítulo, serviu para revelar o aspecto crucial de toda a questão: o fechamento dos dois sistemas pela virtual consolidação das esferas econômica e ecológica transformou os bens ambientais de livres em econômicos, e, portanto, não há como fugir a tratá-los como tais. (NUSDEO: 2015; 422) 
Relações econômicas e garantia de direitos: estudo de caso na comunidade... Jefrei Almeida Rocha • Paulo Venício Braga de Paula • Rosendo Freitas de Amorim

Curiosamente, aquilo que outrora poderia ser considerado um bem livre, ao menos na perspectiva dos indígenas da Encantada, só foi percebido pelos nativos como um bem com valor econômico a partir da necessidade de defesa de sua terra, de sua moradia. Ou seja, foi justamente o objeto de cobiça do grande capital que passou a compor renda para a comunidade, mediante a exploração da atividade hoteleira. Contudo, parece-nos coerente afirmar que a exploração do ramo turístico, além de objetivar a geração de renda, é uma forma de autoafirmação da comunidade e de todos os seus membros.

A tribo desenvolve uma parceria com o Governo do Estado do Ceará, essa parceria contempla o projeto "Vídeo na aldeia" pelo qual os curumins aprendem a fazer filmagens e aprendem uma nova profissão. Apesar disso, a economia se baseia principalmente na pousada. Soma-se a essa renda os lucros com a realização de feiras de artesanato indígena, onde são vendidos cocares, pulseiras, camisas e principalmente a bebida típica, o Mocororó. Também é cobrado um determinado valor para a realização de trilhas ecológicas.

A tribo possui sua economia independente, no entanto, assim como todo cidadão de direito, os seus habitantes necessitam de atenção às suas necessidades básicas. Como exemplo podemos citar o transporte público, para que se faça valer o direito constitucional e natural de ir e vir, no entanto há grande dificuldade de locomoção do povo indígena, muitas vezes não é possível entrar ou sair da tribo devido à inexistência de estradas pavimentadas e à inexistência de transporte público para a comunidade, retratando a dificuldade de garantir os direitos fundamentais da população da tribo.

Segundo Nusdeo (2015), o crescimento, ou melhor, com o agigantamento do sistema econômico, é inevitável um choque entre esse mesmo sistema e o ecológico, uma vez que a origem e o destino dos materiais de que se serve o sistema econômico, na sua atividade produtora, é o sistema ecológico. Como exemplo com- 
Relações econômicas e garantia de direitos: estudo de caso na comunidade... Jefrei Almeida Rocha • Paulo Venício Braga de Paula • Rosendo Freitas de Amorim

para-se com o interesse na exploração da Lagoa Encantada pelo Moinho Dias Branco, bem como a poluição realizada pela Ypióca.

Ainda segundo Nusdeo (2015), a consequência da referida fusão das duas esferas é a de os bens ecológicos começarem a ganhar a condição e as características de bens econômicos, no entanto, em relação ao caso em estudo, não se deu pela escassez, mas pela procura, pelo interesse.

Dessa forma, é válido afirmar que a atividade desenvolvida pela comunidade da Lagoa Encantada apresenta-se como uma integração entre o aspecto conservacionista de uma tradição, com o avanço da atividade econômica, ou seja, uma integração entre o sistema econômico e o ecológico.

\section{Considerações Finais}

A visão integracionista predominou no Brasil na época da Ditadura Militar e, para alcançar esse intuito, os governos militares planejaram e executaram a concessão de terras visando ao desenvolvimento econômico, sendo essa integração das comunidades indígenas uma necessidade para a política de governo.

Uma vez realizada a rápida integração das comunidades indígenas, o índio abandonaria sua cultura e suas tradições, constituindo a força de trabalho necessária para o desenvolvimento econômico do país. Dessa forma, as comunidades não seriam obstáculos e não prejudicariam o desenvolvimento da pátria. Percebe-se que a política governamental pensada para os indígenas era pautada nos interesses políticos e econômicos.

Após uma extensa luta ao longo da história, os povos indígenas passaram a ter seus direitos reconhecidos e protegidos pela Constituição Federal de 1988, significando um verdadeiro avanço no ordenamento jurídico brasileiro. A proteção dos costumes, das línguas, da prática de suas crenças, a manutenção de suas 
Relações econômicas e garantia de direitos: estudo de caso na comunidade... Jefrei Almeida Rocha • Paulo Venício Braga de Paula • Rosendo Freitas de Amorim

tradições e o reconhecimento da organização social nas terras indígenas, levou as sociedades contemporâneas a refletirem sobre o abandono e a segregação sofrida pelos indígenas.

Antropologicamente, a teoria da evolução do índio rumo à civilização foi abandonada, passando-se a defender a questão identitária dos povos originários e a manutenção de sua história, tradição e cultura, sem opor à possibilidade de integração aos avanços e descobertas tecnológicas.

Juridicamente, considera-se que a legislação atual rompeu com a anterior e trouxe a ampla garantia de direitos às comunidades indígenas, abandonando o ideário de processo evolucionário do índio. E, ao menos na tessitura do ordenamento jurídico, as leis buscam garantir que as terras onde os povos originários habitam sejam permanentemente deles, para o usufruto de suas atividades produtivas, para a preservação dos recursos ambientais necessários a seu bem-estar e necessária à sua reprodução física e cultural, resguardado os costumes e tradições.

Reafirmados esses conceitos, compreende-se que as relações sociais e a conduta dos indivíduos que fazem parte da tribo ainda guardam aspectos bem próximos daquilo que a Ciência do Direito define como Direito Natural. Os costumes pautam as decisões internas e as hierarquias, nas quais a vivência e as experiências determinam a tomada de decisões.

É essa a realidade também da comunidade Jenipapo-Kanindé em Aquiraz. Porém, a necessidade de subsistência encontra dificuldades de se manter apenas com as atividades produtivas tradicionais e, ao inovar a atividade produtiva, indo em direção a um mercado tipicamente desenvolvido pelos não-índios, a consequente atuação do direito positivado no cotidiano da tribo se torna mais intenso.

Fica evidente que a nova forma de organizar economicamente a tribo amplia a presença do direito positivado no cotidiano da tribo, tanto em relação à proteção e garantia de direitos, quanto 
Relações econômicas e garantia de direitos: estudo de caso na comunidade... Jefrei Almeida Rocha • Paulo Venício Braga de Paula • Rosendo Freitas de Amorim

ao entendimento dos processos e procedimentos que passaram a fazer parte do cotidiano da tribo.

O fenômeno econômico abordado neste estudo, a pousada na Lagoa da Encantada criado pelos Jenipapo-Kanindé, simboliza um amálgama entre o direito natural e o direito positivo, entre as atividades produtivas tradicionais e uma nova atividade de produção de renda, entre a tradição artesã e de cultivo de alimentos, com o setor de serviços.

Servindo de campo para diversos estudos sobre a temática, no qual a atividade econômica é desenvolvida a partir de uma lógica de sustentabilidade, ou como a própria comunidade cita, de ecoturismo, que respeita e conserva a natureza.

A transformação de bens livres em bens econômicos não é um fenômeno econômico inédito, no entanto, a singularidade do caso em estudo se dá pelo fato de povos originários assumirem o papel de protagonistas nesse processo. Também atestamos que os Estados necessitam apoiar as comunidades tradicionais, indígenas ou não indígenas, na afirmação de suas identidades, na proteção de suas culturas e de seus interesses, de modo a propiciar meios e condições para execução de projetos e ações de desenvolvimento sustentável, bem como na compreensão de como os bens naturais tornam-se bem econômicos.

Nesse contexto, considera-se que a experiência desenvolvida pela tribo indígena em Aquiraz tem muito a contribuir para o entendimento dos impactos e do desenvolvimento de atividades produtivas pouco comuns às comunidades tradicionais, como a realizada pelos Jenipapo-Kanindé. Almeja-se, em estudos futuros, observar a sustentabilidade da proposta de ecoturismo na tribo e quais os riscos dessa nova estrutura de geração de renda. 
Relações econômicas e garantia de direitos: estudo de caso na comunidade... Jefrei Almeida Rocha • Paulo Venício Braga de Paula • Rosendo Freitas de Amorim

\title{
Referências
}

\begin{abstract}
ALMEIDA, L. S., \& FREIRE, T. Metodologia da investigação em psicologia e educação 4. ed. Braga: Psiquilíbrios Edições. 2007

BRASIL. Conselho Nacional de Saúde. (2012). Resolução nº
\end{abstract}

466/12. Disponível em: http://bvsms.saude.gov.br/bvs/saudelegis/cns/2013/res0466_12_12_2012.html. Acesso em: 30 mar. 2017.

BRASIL. Conselho Nacional de Saúde. (2016). Resolução $n^{\circ}$ 510/2016. Disponível em: http://conselho.saude.gov.br/resolucoes/2016/Reso510.pdf. Acesso em: 30 mar. 2017.

\section{BRASIL. Constituição (1988). Constituição da República}

Federativa do Brasil. Disponível em: http://www.planalto.gov.br/ ccivil_03/constituicao/constituicaocompilado.htm. Acesso em: 02 set. 2017.

BRASIL. Ação Civil Pública n 006. Liminar contra invasão de território indígena Jenipapo-Kanindé. Fortaleza, 06 de outubro de 1998.

BRASIL. Lei $n^{\circ} 6.001$ de 19 de dezembro de 1973. Estatuto do Índio. Disponível em: http://www.planalto.gov.br/ccivil_03/leis/ L6001.htm. Acesso em: 21 set. 2017.

BRASIL. Lei 10.406, de 10 de janeiro de 2002. Código Civil. Disponível em: http://www.planalto.gov.br/ccivil_03/leis/2002/ L10406.htm Acesso em: 21 set. 2017.

BEZERRA, Roselane G. O despertar de uma Etnia: o Jogo do (Re)conhecimento da Identidade Indígena Jenipapo-Kanindé. Dissertação (Mestrado)-UFC, Fortaleza, 1999.

FONSECA, J. J. S. Metodologia da pesquisa científica. Fortaleza: UEC, 2002. Apostila.

GALVÃO DE SOUSA, José Pedro. Direito natural, direito positivo e estado de direito. São Paulo: Revista dos Tribunais, 1977. 
Relações econômicas e garantia de direitos: estudo de caso na comunidade... Jefrei Almeida Rocha • Paulo Venício Braga de Paula • Rosendo Freitas de Amorim

Disponível em: https://docslide.com.br/documents/ direito-natural-direito-positivo-e-estado-de-direito-jose-pedro-galvao.html. Acesso em: 21 set.2017.

GIL, A. C. Métodos e técnicas de pesquisa social. 6 ed. São Paulo: Atlas, 2008.

LIMA, Felipe Alexandre de; MARQUESAN, Fábio Freitas Schilling. Terras indígenas no Ceará: uma história de lutas e resistência.

REBELA-Revista Brasileira de Estudos Latino-Americanos, v. 7, n. 3, 2017.

MINAYO, Maria C. Pesquisa social: teoria e método. Petrópolis, Rio de Janeiro: Vozes, 1994.

NADER, Paulo. Introdução ao estudo do direito. 28 ed. Rio de Janeiro: Forense, 2007

NADER, Paulo. Filosofia do Direito. 21. ed. Rio de Janeiro: Forense 2012

NUSDEO, Fábio. Curso de Economia [livro eletrônico]: introdução ao direito econômico. $3^{\mathrm{a}}$ ed. São Paulo: Editora Revista dos Tribunais, 2015. 